\title{
LSD1 dual function in mediating epigenetic corruption of the vitamin D signaling in prostate cancer
}

\author{
Sebastiano Battaglia ${ }^{*}$, Ellen Karasik², Bryan Gillard², Jennifer Williams², Trisha Winchester ${ }^{3}$, Michael T. Moser ${ }^{2}$, \\ Dominic J Smiraglia ${ }^{3}$ and Barbara A. Foster ${ }^{2^{*}}$
}

\begin{abstract}
Background: Lysine-specific demethylase $1 \mathrm{~A}(\mathrm{LSD1})$ is a key regulator of the androgen (AR) and estrogen receptors $(E R)$, and LSD1 levels correlate with tumor aggressiveness. Here, we demonstrate that LSD1 regulates vitamin D receptor (VDR) activity and is a mediator of $1,25(\mathrm{OH})_{2}-\mathrm{D}_{3}$ (vitamin D) action in prostate cancer (PCa).

Methods: Athymic nude mice were xenografted with CWR22 cells and monitored weekly after testosterone pellet removal. Expression of LSD1 and VDR $(\mathrm{IHC})$ were correlated with tumor growth using log-rank test. TRAMP tumors and prostates from wild-type (WT) mice were used to evaluate VDR and LSD1 expression via IHC and western blotting. The presence of VDR and LSD1 in the same transcriptional complex was evaluated via immunoprecipitation (IP) using nuclear cell lysate. The effect of LSD1 and $1,25(\mathrm{OH})_{2}-\mathrm{D}_{3}$ on cell viability was evaluated in C4-2 and BC1A cells via trypan blue exclusion. The role of LSD1 in VDR-mediated gene transcription was evaluated for Cdkn1a, E2f1, Cyp24a1, and S100g via qRT-PCR-TaqMan and via chromatin immunoprecipitation assay. Methylation of Cdkn1a TSS was measured via bisulfite sequencing, and methylation of a panel of cancer-related genes was quantified using methyl arrays. The Cancer Genome Atlas data were retrieved to identify genes whose status correlates with LSD1 and DNA methyltransferase 1 (DNMT1). Results were correlated with patients' survival data from two separate cohorts of primary and metastatic PCa.
\end{abstract}

Results: LSD1 and VDR protein levels are elevated in PCa tumors and correlate with faster tumor growth in xenograft mouse models. Knockdown of LSD1 reduces PCa cell viability, and gene expression data suggest a dual coregulatory role of LSD1 for VDR, acting as a coactivator and corepressor in a locus-specific manner. LSD1 modulates VDR-dependent transcription by mediating the recruitment of VDR and DNMT1 at the TSS of VDR-targeted genes and modulates the epigenetic status of transcribed genes by altering H3K4me2 and H3K9Ac and DNA methylation. Lastly, LSD1 and DNMT1 belong to a genome-wide signature whose expression correlates with shorter progression-free survival and overall survival in primary and metastatic patients' samples, respectively.

Conclusions: Results demonstrate that LSD1 has a dual coregulatory role as corepressor and coactivator for VDR and defines a genomic signature whose targeting might have clinical relevance for PCa patients.

\footnotetext{
* Correspondence: sebastiano.battaglia@roswellpark.org;

barbara.forster@roswellpark.org

${ }^{1}$ Center for Immunotherapy, Roswell Park Cancer Institute, Elm and Carlton

St, Buffalo, NY 14263, USA

${ }^{2}$ Department of Pharmacology and Therapeutics, Roswell Park Cancer

Institute, Elm and Carlton St, Buffalo, NY 14263, USA

Full list of author information is available at the end of the article
} 


\section{Background}

Prostate cancer $(\mathrm{PCa})$ is the most commonly diagnosed cancer in men in the USA and the second leading cause of cancer death [1]. The secosteroid hormone 1,25-dihydroxy-vitamin $\mathrm{D}_{3}\left(1,25-\mathrm{D}_{3}\right)$ binds to the vitamin $\mathrm{D}$ receptor (VDR), which translocates into the nucleus, binds to VDR-responsive elements (VDREs), and associates with coregulatory complexes to either activate or repress gene transcription. $1,25-\mathrm{D}_{3}$ is metabolized by the VDR target gene CYP24A1 [2] and activates a number of downstream metabolic pathways including calcium absorption through induction of S100g [3] and maintenance of bone health [4-6] and cellular pathways regulating cell differentiation and proliferation [7-10]. 1,25- $\mathrm{D}_{3}$-bound VDR can cause cell cycle arrest by targeting G0S2, CDKN1A [11, 12], IGFBP3 [13], and E2F target genes [14]. Furthermore, $1,25-\mathrm{D}_{3}$ can induce apoptosis by repressing $\mathrm{WNT} / \beta$-catenin signaling, as shown in $\mathrm{Vdr}^{-/-}$mice [15], and by targeting c-Myc [16] and inhibiting the expression of the anti-apoptotic genes $\mathrm{Bcl} 2$ and $\mathrm{BclXL}$ [17]. As $1,25-\mathrm{D}_{3}$ has a potent antiproliferative effect on prostate epithelial cells, late-stage $\mathrm{PCa}$ frequently loses sensitivity to numerous nuclear receptor (NR) ligands, including $1,25-\mathrm{D}_{3}[18,19]$. Numerous mechanisms describing loss of $1,25-\mathrm{D}_{3}$ responsiveness have been proposed including VDR mutations [20-22], differential recruitment of coregulatory proteins [19, 23-25], and changes in the epigenetic landscape of tumor cells [26-29].

The lysine-specific demethylase 1A (LSD1/KDM1A) is a demethylating enzyme that targets mono- and dimethylH3K4 [30], associated with open chromatin structure permissive to transcription, and dimethyl-H3K9 [31], associated with close chromatin structure and transcriptional repression. LSD1 also targets non-histone proteins such as TP53, repressing p53-targeted gene activation [32], and DNA methyltransferase 1 (DNMT1), promoting protein stability and maintenance of $\mathrm{CpG}$ methylation [33]. LSD1 is overexpressed in numerous cancers including bladder [34], breast [35], brain [36], and prostate [31], underlying LSD1 clinical relevance across multiple malignancies. Given the frequency of overexpression as well as its role in regulating transcriptional outcomes of NRs, LSD1 is being investigated as a novel clinical target for cancer patients with promising in vitro results $[36,37]$.

In this study, we describe for the first time LSD1 acting as transcriptional corepressor and coactivator for VDR, and we propose a mechanism by which LSD1 modulates VDR-dependent epigenetic regulation of gene transcription. We also define DNMT1 as a key player in the epigenetic changes regulated by LSD1, ultimately defining a VDR/LSD1/DNMT1 genomic signature that correlates with clinical outcome of patients with PCa.

\section{Methods}

\section{Cell culture and treatments}

$\mathrm{BC} 1 \mathrm{~A}$ cells used in this manuscript were isolated by $\mathrm{BF}$ and $\mathrm{MM}$ from a bone metastasis in a TRAMP mouse (FVB:C57BL/6 50:50 strain background) [38, 39]. BC1A cells were established by three rounds of clonal dilutions and were used as a model for $1,25-\mathrm{D}_{3}$ resistance. C4-2 cells were obtained from Dr. Leland Cheung (Cedars-Sinai Medical Center), and CWR22 cells were a kind gift from Dr. Thomas G. Pretlow (Case Western Reserve University). C4-2 and CWR22 cells were validated via microsatellite PCR at the Roswell Park Cancer Institute (RPCI) Genomics Core. BC1A cells are a murine inhouse-derived cell line. BC1A cells were maintained in DMEM (Gibco) media supplemented with 10\% FBS (Gibco, 26,140-079), $5 \mu \mathrm{g} / \mathrm{mL}$ of insulin (Invitrogen, 12585-014), $10 \mathrm{nM}$ DHT (Sigma, D-073-1ML), and penicillin/streptomycin (Invitrogen, 15140-122). C4-2 cells were maintained in RPMI1640 (Gibco) with 10\% FBS and penicillin/streptomycin. CWR22 were used only for in vivo experiments, as described below.

\section{Mice and tumor xenograft}

This study was approved by the RPCI and Institutional Animal Care and Use Committee (RPCI/IACUC) and carried out by the Mouse Tumor Model Resource (MTMR) Core at RPCI. Six-week-old athymic nude (Hsd:Athymic Nude-Foxn1nu) mice $(n=50)$ were purchased from Envigo (069(nu)/070(nu/+)). The mice were castrated, and testosterone (Sigma T1500-25G) pellets (13 $\mathrm{mg} /$ mouse) were implanted subcutaneously. The mice were subsequently injected subcutaneously with $10^{6}$ CWR22 cells in matrigel (Corning 354234). Tumors were assessed weekly via caliper measurement, and tumor volume was calculated using the following formula: $\left[\left(\operatorname{dim}_{\text {(short) }}\right)^{2}\right]^{*}\left[\operatorname{dim}_{(\text {long })}\right] * 0.5324$. Testosterone pellets were removed (castration) once tumors reached $200 \mathrm{~mm}^{3}$, and tumor volume was measured weekly for 45 weeks. Mice that never developed tumors or mice that died before pellet removal were excluded from the study. The mice were euthanized either when signs of toxicity appeared (lethargy, paleness, hunched back, loss of weight) or when tumors reached $2 \mathrm{~cm}$ in any direction as per institutional guidelines. At the time of death, tumors were resected and utilized for immunohistochemistry analysis.

\section{Immunohistochemistry (IHC)}

Tissues were fixed in $10 \%$ buffered formalin for $24 \mathrm{~h}$ prior to processing. Tissues were processed and embedded in paraffin and then sectioned at $5 \mu \mathrm{m}$. Slides were deparaffinized in several baths of xylene and then rehydrated in graded alcohols followed by $\mathrm{ddH}_{2} \mathrm{O}$. Slides were incubated in $1 \times \mathrm{pH} 6$ citrate buffer (Invitrogen, 00-5000) in DAKO 
PT Link for 20 min. IHC was performed using DAKO Autostainer Plus following manufacturer's instructions. Slides were incubated in $3 \% \mathrm{H}_{2} \mathrm{O}_{2}$ for 15 min. To block non-specific binding, tissues were incubated with $10 \%$ normal goat serum for $30 \mathrm{~min}$, followed by avidin/biotin block (Vector Labs, SP-2001). Primary antibody LSD1 (Cell Signaling, 2139) or VDR (Thermo Scientific MA1710 (Clone 9A7)) were diluted in 1\% BSA solution and incubated for $30 \mathrm{~min}$ at room temperature, followed by the biotinylated Goat Anti-Rabbit secondary antibody (Abcam, ab6720) for 15 min. For signal enhancement, ABC reagent (Vector Labs, PK-6100) was applied for 30 min. Slides were then incubated with DAB substrate (Dako, K3467) for $5 \mathrm{~min}$ and then counterstained with DAKO hematoxylin for 20 s. Slides were dehydrated through several baths of graded alcohols and xylenes and then coverslipped. Finally, slides were scanned using the Aperio System (Leica).

\section{Western blotting}

When murine tissues were used, the dorsal, lateral, and ventral prostates were microdissected from wild-type and TRAMP mice. The prostates were resuspended in $300 \mu \mathrm{l}$ RIPA buffer and minced using tissue homogenizer (Polytron, PT1035). Lysates were centrifuged at $16,000 \mathrm{rpm}$ for 10 min at $+4{ }^{\circ} \mathrm{C}$, and clear supernatant was recovered. When cell lines were used, nuclear and cytoplasmic lysates were extracted using the NE-PER kit (Thermo Scientific, 78833) following the manufacturer's instructions. Protein concentration was quantified using the Bio-Rad RC-DC protein assay kit (Biorad, 500-0121). Forty micrograms of protein were loaded onto a 10\% SDS gel (Biorad) and ran for $90 \mathrm{~min}$ at $120 \mathrm{~V}$. Proteins were transferred onto a PVDF membrane (Invitrogen, LC2002) using Biorad transfer buffer (Biorad 161-0771) for $110 \mathrm{~min}$ at $80 \mathrm{~V}$ at + $4{ }^{\circ} \mathrm{C}$. Next, the membrane was blocked with $5 \%$ milk in TBST for $1 \mathrm{~h}$ at RT, incubated overnight with LSD1 (Cell Signaling 2139), VDR (Thermo Scientific MA1710 (Clone 9A7)), or GAPDH (Cell Signaling 2118) primary antibody, incubated with secondary HRP-conjugated secondary antibody (Santa Cruz sc-2030) and developed using chemoluminescent reaction (Pierce, 32132).

\section{Immunoprecipitation (IP)}

Nuclear proteins were extracted using the NE-PER Nuclear and Cytoplasmic Extraction Kit (Thermo Scientific, 78833), and lysates were pre-cleared with $\mathrm{A} / \mathrm{G}$ agarose beads (Millipore, LSKMAGA02) for $1 \mathrm{~h}$ at $4{ }^{\circ} \mathrm{C}$. LSD1 antibody (Cell Signaling 2139) at 1:50 dilution and IgG Rabbit (Santa Cruz, 2027) at 1:500 dilution were added to each sample and incubated on a rotator over night at $4{ }^{\circ} \mathrm{C}$. The pulldown of LSD1 antibody and IgG control was achieved by adding A/G agarose beads to the samples and incubating them on a rotator for $3 \mathrm{~h}$ at $4{ }^{\circ} \mathrm{C}$.
Samples were then used for western blot analysis using the following antibodies: LSD1 (Cell Signaling, 2139) and VDR (Santa Cruz Sc-13133 (Clone D-6)).

\section{Survival analysis}

Survival analysis for mice with high/low LSD1 and VDR tumor protein levels was done using $R$ and the package survival. IHC slides were scored as "low" (negative/low staining) or positive (medium/strong staining), and the mice were grouped accordingly. Since tumor reaching $1000 \mathrm{~mm}^{3}$ tends to keep proliferating till reaching the size limit imposed by the RPCI LAR/IACUC $(2 \mathrm{~cm}$ in any dimension), tumor recurrence was defined as tumor reaching $1000 \mathrm{~mm}^{3}$ after castration. Data were analyzed in $R$ [40] with the survival package [41], and log-rank test was used to assess the difference in time to recurrence in the high vs. low groups with a significance threshold of $p$ value $<0.05$.

\section{Cell transfection}

siRNA transfection: BC1A cells were transfected with small interfering RNA (siRNA) for LSD1 or scrambled siRNA control (Ambion, s97504 and 12935-200) using Lipofectamine 2000 (Invitrogen, 11668027), following the manufacturer's instructions. Briefly, siRNA and Lipofectamine were diluted in OptiMEM (Invitrogen 11058021); siRNA/lipid complexes were then added to BC1A cells in the OptiMEM with 5\% FBS. Cells were incubated overnight before replacing media with full DMEM. shRNA transfection: BC1A and C4-2 cells were prepared at the RPCI small hairpin RNA (shRNA) Core facility. Briefly, the cells were stably transfected with scrambled shCTR (Dharmacon, RHS4346) and murine shLSD1 (Dharmacon, RMM4431) for BC1A or human shLSD1 (Dharmacon, RHS4430) for C4-2 cells. Cells transfected with shRNA were maintained in complete media with $2 \mu \mathrm{g} / \mathrm{mL}$ of puromycin (Invitrogen, A1113803).

\section{Cell viability assay}

BC1A cells transfected with siCTR/siLSD1 or C4-2 cells transfected with shCTR/shLSD1 were treated with $100 \mathrm{nM}$ $1,25-\mathrm{D}_{3}$ or vehicle control and incubated for $72 \mathrm{~h}$ at $37^{\circ} \mathrm{C}$. Cells were collected using trypsin (Sigma, T4049), and viable cells were counted via trypan blue exclusion using the automatic cell counter (Beckman Coulter, ViCellXR). Cell counts were normalized to vehicle-treated cells, and statistical significance was calculated using twoway ANOVA with post hoc Tukey test using GraphPad Prism.

\section{Gene expression analysis}

BC1A cells transfected with siCTR/siLSD1 were treated for 4 or $24 \mathrm{~h}$ with $100 \mathrm{nM} 1,25-\mathrm{D}_{3}$. Media was removed, and the cells were washed and resuspended in $1 \mathrm{~mL}$ of 
TRI Reagent (Ambion, AM9738). RNA was extracted following the manufacturer's directions. RNA was quantified using ThermoScientific NanoDrop 8000, and $1 \mu \mathrm{g}$ of RNA was reverse-transcribed into cDNA using the SuperScript First Strand Synthesis kit (Invitrogen, 11904-018). qRTPCR-TaqMan primers for Lsd1, E2f1, Cdkn1a, Cyp24a1, and S100g were ordered from Applied Biosystems (Mm01181042_m1 Mm00432936_m1, Mm00432448_m1, Mm00407244_m1, and Mm00486654_m1, respectively). qRT-PCR universal MasterMix (Roche) was used. Data were normalized to beta-actin (Applied Biosystems, Mm00607939_s1) and fold changes (FC) calculated using the $2^{\wedge}$-ddCt formula using shCTR vehicle treated as control. Statistical significance was evaluated by two-way ANOVA with post hoc Tukey test using the GraphPad Prism. For tissues, mRNA from the ventral, lateral, and dorsal prostates was extracted by homogenizing the tissues and using TRI Reagent, following the manufacturer's instructions. Five samples per age group were used.

\section{Chromatin immunoprecipitation}

Primers are listed in Additional file 1: Table S3. Exponentially growing shLSD1-BC1A and shCTR-BC1A cells were incubated with $100 \mathrm{nM} 1,25-\mathrm{D}_{3}$ for $24 \mathrm{~h}$, crosslinked with $1 \%$ formaldehyde, and incubated with L-glycine to stop the reaction. Cell pellet was collected in cold PBS and nucleic extract prepared using the MC lysis buffer $(10 \mathrm{mM}$ Tris $\mathrm{HCl} \mathrm{pH} 7.5,10 \mathrm{mM} \mathrm{NaCl}$, $\left.3 \mathrm{mM} \mathrm{MgCl}_{2}, 0.5 \%(v / v) \mathrm{NP}-40\right)$. After centrifugation, the pellets were resuspended in MNase digestion buffer (10 mM TrisHCl pH 7.5, $10 \mathrm{mM} \mathrm{NaCl}, 3 \mathrm{mM} \mathrm{MgCl}_{2}$, $1 \mathrm{mM} \mathrm{CaCl}_{2}, 4 \%(v / v)$ NP-40, $1 \mathrm{mM}$ phenylmethane sulfonyl fluoride (PMSF)) and incubated with 100 units of micrococcal nuclease enzyme for $11 \mathrm{~min}$ at $37{ }^{\circ} \mathrm{C}$. Per each sample, digestion was stopped with the addition of EGTA, PMSF, protease inhibitor, SDS, and $\mathrm{NaCl}$. Following $5 \mathrm{~min}$ sonication (Bioruptor), the samples were centrifuged at a maximum speed for $10 \mathrm{~min}$ at $+4{ }^{\circ} \mathrm{C}$ and the supernatant was collected for further analysis. Two hundred microliters of the supernatant were diluted with $300 \mu \mathrm{L}$ dilution buffer $(0.01 \%$ SDS, $1.1 \%$ Triton X100, 1.2 mM EDTA, $16.6 \mathrm{mM}$ TrisHCl pH 8.1, $167 \mathrm{mM}$ $\mathrm{NaCl}$ ) and incubated with the primary antibody overnight at $+4{ }^{\circ} \mathrm{C}$ on a rotating platform. The antibodies used are the following: IgG (Santa Cruz, sc-2027/sc2025), histone 3 lysine 4 dimethylated (H3K4me2-Abcam, ab32356), histone 3 lysine 4 acetylated (H3K9Ac-Abcam, ab4441), DNA methyltransferase 1 (DNMT1-Abcam, ab92453), and vitamin D receptor (VDR-Santa Cruz, sc1008-x). Antibody-protein complexes were retrieved using MagnaCHIP magnetic beads (Millipore, 16-663) after washes of 5 min each with high salt buffer, low salt buffer, $\mathrm{LiCl}$ buffer, TE buffer, and elution buffer $\left(0.1 \mathrm{M} \mathrm{NaHCO}_{3}, 1 \%\right.$ SDS). Finally, DNA was extracted using standard phenol chloroform protocol. Quantitation of the DNA fragments was done using qRT-PCR-SYBRGREEN with the Universal SYBR Green Mastermix (Bio-Rad, 172-5124). Ct values were normalized to the INPUT control and plotted as percentage of INPUT. Statistical significance was evaluated by two-way ANOVA with post hoc Tukey test using the GraphPad Prism.

\section{DNA methylation analysis}

Stably transfected BC1A cells were plated in a 6-well plate and treated for $24 \mathrm{~h}$ with $100 \mathrm{nM} 1,25-\mathrm{D}_{3}$ or vehicle control. DNA was extracted using the DNeasy kit from Qiagen following the manufacturer's directions. DNA was bisulfite-treated using the EZ DNA Methylation kit (Zymo Research, D5002), amplified (p21FW: ag gaagagagGGTGAAGGAGTGGGTTGGTTT, p21RW: ca gtaatacgactcactatagggagaaggctTCCACTCATCACCACA CACA), cloned using the TA cloning kit (Invitrogen), and sequenced at the RPCI Sequencing Core. DNA for the methylation array was digested following SABiosciences instructions to create samples corresponding to undigested, methylation-sensitive and methylation-dependent, and both conditions. Qiagen arrays were run on an ABI 7900 thermo cycler following the manufacturer's guidelines. Data analysis was carried out using the template analysis file offered by SABiosciences. The analysis includes quality control steps that evaluate the quality of the enzymatic digestion and reports the percentage of methylation per each gene. Differential methylation analysis was done by building linear models comparing the average methylation levels in two conditions using $R$ and calculating the 95th percentile intervals. Genes whose average methylation levels fell outside the 95th percentiles were deemed significant.

\section{Regulome Explorer analysis, TCGA data retrieval, and functional enrichment analysis}

The Regulome Explorer tool is freely available at http://explorer.cancerregulome.org/. It contains gene expression, DNA methylation, CNVs, SNPs, miRNA expression, and clinical data for the samples available through TCGA (http://cancergenome.nih.gov/) on July 2016. The analysis was performed with 333 PCa clinical samples. Using a gene name (or more), the tool retrieves all the data that significantly correlate with the data available for the query gene(s). Statistical significance of each pairwise association (i.e., LSD1 vs. all and DNMT1 vs. all) is assessed using rank-ordered data and a statistical test appropriate to each data type pair, e.g., Fisher's test (categorical-categorical), F statistic (continuous-continuous), and ANOVA (continuous-categorical). The top 20 significantly correlated genes were used to query the freely accessible cBioPortal tool to query the TCGA provisional (491 samples under "All Complete Tumors") and Metastatic 
Michigan (61 samples under "tumors with sequencing and CNA") data (http://www.cbioportal.org/index.do). Functional enrichment analysis was run with the Broad's molecular signature database (http://software.broadinstitute.org/ gsea/index.jsp) with a false discovery rate $(\mathrm{FDR})<0.05$.

\section{Results}

\section{LSD1 and VDR are upregulated in advanced and CR-PCa}

\section{samples}

LSD1 protein levels were evaluated in age-matched wildtype (WT) and TRAMP mice by immunohistochemical (IHC) and western blot (WB) analysis. LSD1 mRNA levels moderately vary during disease progression with less than a twofold change ever detected (Additional file 1: Figure S1). We then used whole cell lysates from WT and TRAMP prostates to quantify LSD1 and VDR protein expression. While LSD1 and VDR abundance does not vary in WT samples (Fig. 1a), TRAMP prostates show elevated expression of both proteins, with the highest levels observed in late-stage disease between 15 and 25 weeks of age and in castration-recurrent (CR) tumors (Fig. 1a). Overall, the expression pattern of LSD1 and VDR, normalized to GAPDH, was higher in TRAMP tumors than in WT prostates (Fig. 1b) (LSD1 $p=0.0002$, VDR $p=0.0065$ ). Interestingly, two isoforms of LSD1 were detected in the tumor samples, in accordance with the previously published data [42]. We then evaluated via IHC the cellular localization, which showed a strong nuclear staining for LSD1 and VDR in poorly differentiated PCa (Fig. 1c), corroborating the WB result. The findings in our system are in accordance with the previously published data [43-45], suggesting that LSD1 and VDR levels increase during disease progression in vivo.

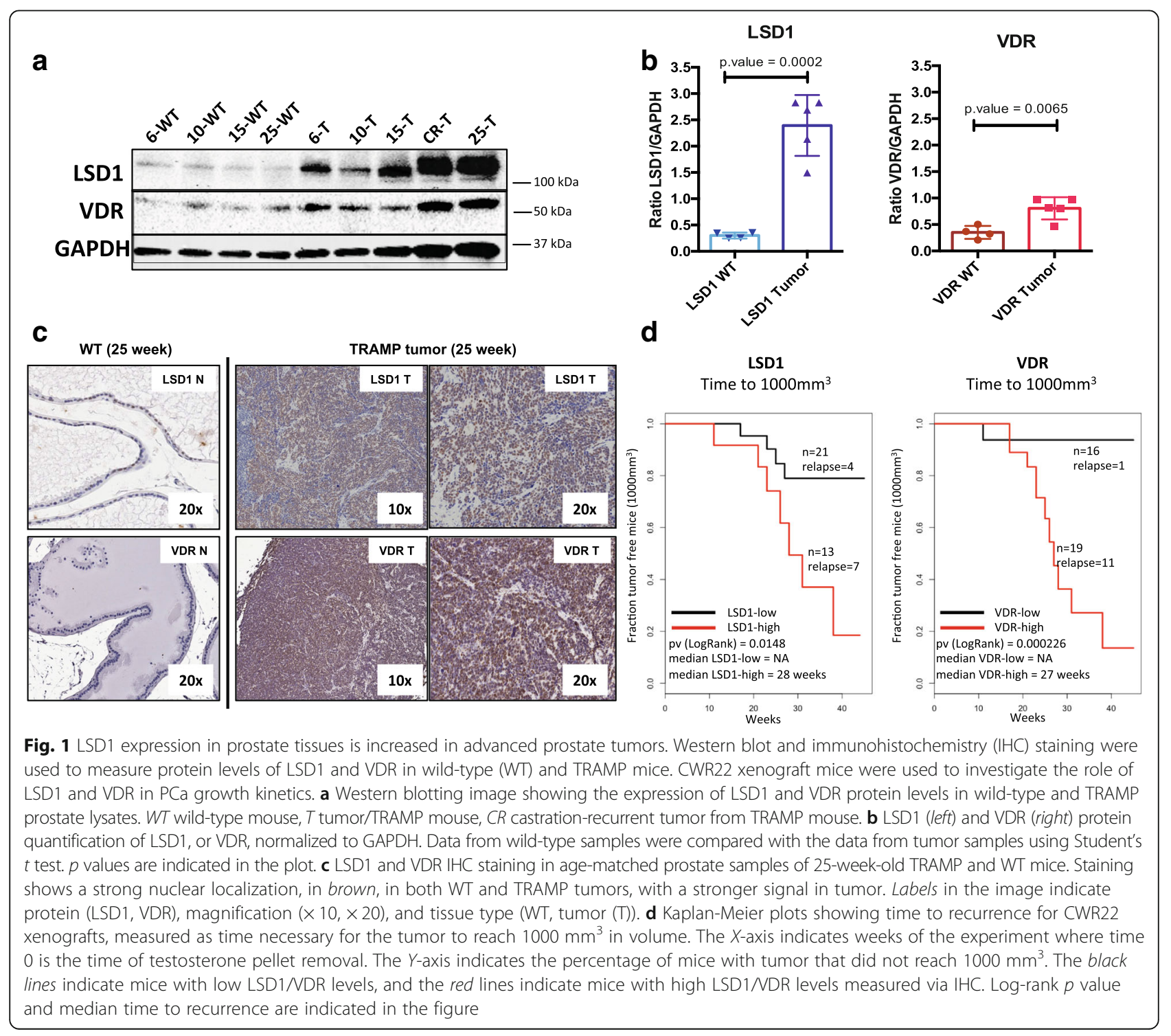




\section{LSD1 and VDR levels correlate with tumor recurrence in vivo}

To evaluate whether increased expression of LSD1 and VDR affects the rate of tumor growth and tumor recurrence in vivo, CWR22 cells were injected subcutaneously in castrated athymic nude mice implanted with testosterone pellets. Once the tumors reached $200 \mathrm{~mm}^{3}$, androgen deprivation therapy (ADT) was mimicked by surgically removing the testosterone pellets and the tumor volume was monitored weekly. At the end of the study, resected tumors were stained with VDR or LSD1 antibodies and mice were scored as "high" or "low" based on the intensity of the staining (Additional file 1: Figure S2). Censored survival analysis was performed to evaluate whether tumors in mice with high levels of LSD1 or VDR grew faster than those in mice with low levels of LSD1 or VDR, measured as time for the tumor to reach $1000 \mathrm{~m}^{3}$ from the time of pellet removal. Results show that mice with high levels of either LSD1 or VDR have significantly shorter time to event than mice with low levels of LSD1 or VDR (log-rank $p=0.0148$ (LSD1), $p=0.00026$ (VDR)) (Fig. 1d). These results suggest that LSD1 and VDR might contribute to the development of CR-PCa in vivo by promoting the establishment of a proliferative phenotype.

\section{LSD1 and VDR belong to the same transcriptional complex}

In order to assess whether LSD1 and VDR belong to the same macro-molecular complex, LSD1 was pulled down in BC1A cells after 24-h exposure to $100 \mathrm{nM} 1,25-\mathrm{D}_{3}$ or vehicle control and samples were probed for VDR. BC1A is a clonal cell line isolated from a bone metastasis in a TRAMP mouse in a FVB:C57BL/6 50:50 strain background and was chosen because it was derived from a naturally developed, and rare, bone metastasis in an in vivo model of PCa. To avoid introducing technical biases, we utilized the same LSD1 antibody used for western blotting and IHC analysis. As in the previous blotting experiment, two isoforms of LSD1 were detected [42] in the pulled down samples. When the samples were probed for VDR, VDR was detected in both the vehicle- and 1,25- $\mathrm{D}_{3}$-treated samples (Fig. 2a). This indicates that LSD1 and VDR interact indirectly by belonging to the same multi-protein complex. Furthermore, the presence

\section{a}

\begin{tabular}{|c|c|c|}
\hline$A b$ & $\lg G$ & LSD1 \\
\hline$V D R$ & & 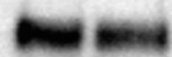 \\
\hline LSD1 & & $=2$ \\
\hline $1,25-D_{3}$ & - & + \\
\hline
\end{tabular}

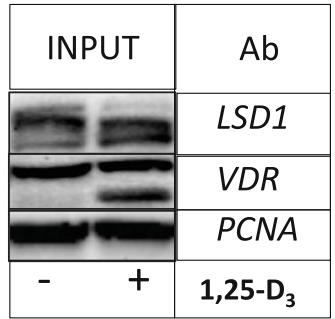

b

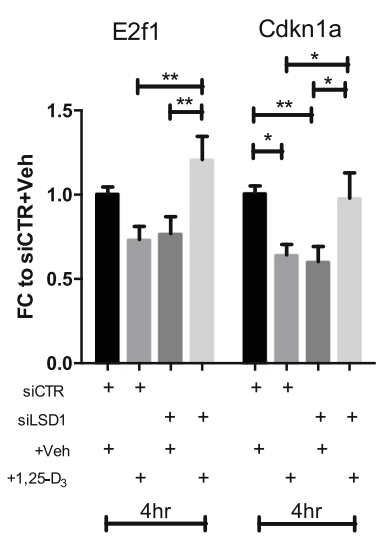

C

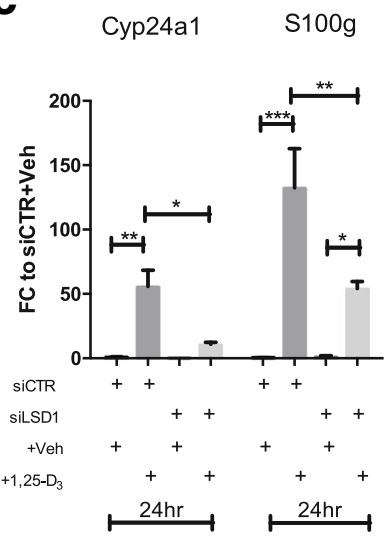

Fig. 2 a Immunoprecipitation (IP) and western blotting (WB) data showing that LSD1 and VDR belong to the same transcriptional complex. IP was performed from nuclear lysate in samples treated with vehicle control or 1,25- $D_{3}$ using the same LSD1 antibody described for IHC and WB. In post-IP, the samples were probed for LSD1 and VDR. The same double band visible in Fig. 1 was also detected in this sample. $\mathbf{b}, \mathbf{c}$ Effect of LSD1 knockdown and 1,25- $\mathrm{D}_{3}$ treatment on gene expression of VDR target genes. Every graph compares the effect of vitamin $\mathrm{D}$ in control (CTR) cells and LSD1 knockdown (siLSD1) cells. Each bar is the mean of at least three biological replicates with SEM, showing the fold changes of treated (+ D3) vs. vehicle-treated (-Veh) samples. The columns indicate, from left to right, siCTR + Veh, siCTR + 1,25-D ${ }_{3}$, siLSD1 + Veh, and siLSD1 + 1,25-D Transcript levels were measured for $\mathbf{b}$ E2f1 and Cdkn1a and c Cyp24a1 and S100g. Statistical significance was evaluated with one-way ANOVA and Tukey post hoc correction $\left({ }^{* *} p<0.001,{ }^{* *} p<0.01,{ }^{*} p<0.05\right)$ 
of VDR in the nucleus of untreated cells is consistent with the ligand-independent repressive role of NRs [46, 47], which can be rescued by $1,25(\mathrm{D})_{3}$-mediated transactivation. Overall, these results suggest that LSD1 and VDR belong to the same nuclear transcriptional complex, independently from the presence of $1,25-\mathrm{D}_{3}$.

\section{LSD1 regulates VDR activity in a gene-specific manner}

Since LSD1 and VDR belong to the same transcriptional complex, we sought to investigate whether LSD1 can regulate the transcription of VDR target genes. As 1,25$\mathrm{D}_{3}$ affects cell proliferation by regulating CDKN1A expression [12] and E2F target genes [14], we quantified Cdkn1a and E2f1 transcript levels in BC1A cells transfected with siRNA targeting LSD1, or scrambled siRNA (Additional file 1: Figure S3A), and treated with 1,25- $\mathrm{D}_{3}$. Furthermore, since $1,25-\mathrm{D}_{3}$ is metabolized by CYP24A1 [48], and $\mathrm{S} 100 \mathrm{~g}$ is a key player in $1,25-\mathrm{D}_{3}$-mediated calcium absorption [3], both Cyp24a1 and S100g transcript levels were quantified via qRT-PCR. LSD1 knockdown significantly reduces $C d k n 1 a$ levels and modestly downregulates E2f1 transcript (Fig. 2b). Similarly, 1,25- $\mathrm{D}_{3}$ treatment significantly downregulates $C d k n 1 a$, with a similar pattern observed for E2f1, suggesting that VDR actively represses Cdkn1a and E2f1 transcription at this time point. Interestingly, LSD1 knockdown inhibits $1,25-\mathrm{D}_{3}$-mediated repression on both genes, leading to increased E2f1 and Cdkn1a gene expression (Fig. 2b). A minimal response to $1,25-\mathrm{D}_{3}$ treatment was still detected after $24 \mathrm{~h}$ (Additional file 1: Figure S4A), suggesting that E2f1 and Cdkn1a are fast responders to $1,25-D_{3}$. These data indicate that at basal levels, LSD1 contributes to the maintenance of Cdkn1a and E2f1 transcription, hence the downregulation of both transcripts upon LSD1 knockdown. Conversely, in the presence of
1,25- $\mathrm{D}_{3}$, LSD1 mediates a rapid VDR-dependent downregulation of Cdkn1a and E2f1; in the absence of LSD1, this inhibitory effect is lost, therefore relieving Cdkn1a and E2f1 transcriptional inhibition with subsequent increase in the transcript levels.

In contrast, $1,25-\mathrm{D}_{3}$ treatment upregulates Cyp24a1 and $S 100 \mathrm{~g}$ transcripts at $24 \mathrm{~h}$, while combination of LSD1 knockdown and $1,25-\mathrm{D}_{3}$ treatment reduces Cyp24a1 and $5100 \mathrm{~g}$ levels of more than 50\% (Fig. 2c). These results indicate that in this context, LSD1 acts as a coactivator for VDR, hence the reduction of Cyp24a1 and S100g transcript levels in LSd1 knockdown cells treated with 1,25$\mathrm{D}_{3}$. Furthermore, Cyp24a1 is not significantly induced at $4 \mathrm{~h}$ while $5100 \mathrm{~g}$ accumulation is significantly higher in the knockdown-treated cells at $4 \mathrm{~h}$ (Additional file 1: Figure S4B), suggesting that Cyp24a1, and to a lesser extent $\mathrm{S} 100 \mathrm{~g}$, are late responders to $1,25-\mathrm{D}_{3}$ stimulation.

Overall, LSD1 appears to have a dual regulatory function for VDR, with a degree of time and locus specificity for different VDR target genes.

\section{LSD1 affects cell viability}

The effect of altered levels of LSD1 on cell viability was tested on BC1A and C4-2 cells. BC1A and C4-2 cells retain minimal $1,25-\mathrm{D}_{3}$ responsiveness, as measured by a reduction in cell viability (Fig. 3). In absence of treatment, LSD1 knockdown leads to a modest but significant reduction in viability in $\mathrm{BC} 1 \mathrm{~A}$ and $\mathrm{C} 4-2$ cells; however, after $72 \mathrm{~h}$ of exposure to $100 \mathrm{nM} 1,25-\mathrm{D}_{3}$, LSD1 knockdown further enhanced the response to $1,25-\mathrm{D}_{3}$ in C4-2 cells but not in BC1A cells (Fig. 3). These results indicate that LSD1 might play a combinatorial role with VDR in regulating cell viability; however, it appears that other factors contribute to $1,25-\mathrm{D}_{3}$ resistance in $\mathrm{BC} 1 \mathrm{~A}$ cells.
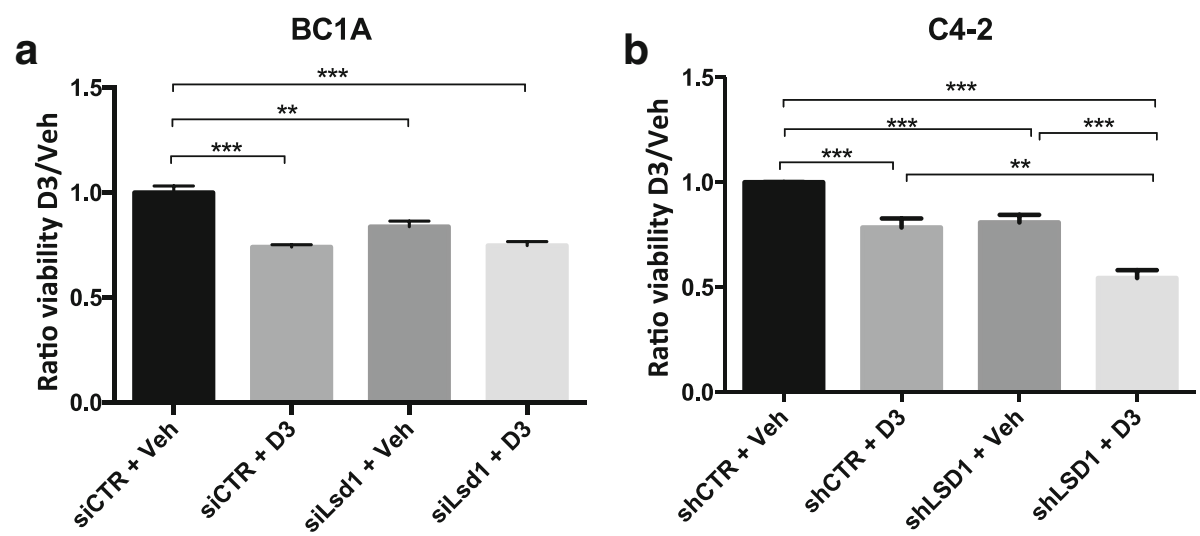

Fig. 3 Viability of $\mathbf{a}$ BC1A and $\mathbf{b}$ C4-2 cells as measured via cell count upon LSD1 knockdown and 1,25-D treatment. Each bar represents the mean of at least three biological replicates, and the $Y$-axis indicates the percentage of viable cells compared to the control. From left to right, in both graphs, the columns indicate shCTR + Veh, shCTR + $100 \mathrm{nM}$ 1,25- $\mathrm{D}_{3}$, shLSD1 + Veh, and shLSD1 + $100 \mathrm{nM} 1,25-\mathrm{D}_{3}$. Statistical significance was evaluated with one-way ANOVA and Tukey post hoc correction $\left({ }^{* * *} p<0.001,{ }^{* *} p<0.01,{ }^{*} p<0.05\right)$ 


\section{LSD1 recruits transcriptional complexes on TSS regions upon VDR activation}

In order to evaluate the mechanism of $1,25-\mathrm{D}_{3}$ resistance in BC1A cells, chromatin immunoprecipitation (ChIP) was performed. LSD1 binding was quantified at the Cdkn1a, E2f1, Cyp24a1, and S100g promoters (Additional file 1: Figure S5). LSD1 is detected and significantly enriched over IgG controls at all loci (Additional file 1: Figure S6); however, LSD1 accumulation is not altered by $1,25-\mathrm{D}_{3}$ treatment, suggesting that LSD1 works in concert with, or modulates the activity of, other components of the transcriptional complex to modulate VDR transcriptional effects.

To identify the factors involved in VDR-mediated transcriptional program, ChIP analysis was performed using the $\mathrm{BC} 1 \mathrm{~A}$ cells stably transfected with either scrambled short hairpin control (BC1A-shCTR) or short hairpin targeting Lsd1 (BC1A-shLSD1) in presence and absence of $1,25-\mathrm{D}_{3}$ (Additional file 1: Figure S3B, C, Fig. 4). We evaluated the binding levels of VDR, as primary mediator of $1,25-\mathrm{D}_{3}$ function, and DNMT1, since LSD1 activity demethylates and stabilizes DNMT1 $[33,49]$ and since $1,25-\mathrm{D}_{3}$ alters DNA methylation [27] in PCa. Lastly, we evaluated the abundance of the activation marks H3K4me2 and H3K9Ac. Twenty four hour treatment with $100 \mathrm{nM}$ of $1,25-\mathrm{D}_{3}$ increases DNMT1 binding and reduces H3K9Ac at the Cdkn1a TSS (Fig. 4a). Interestingly, LSD1 knockdown also increases DNMT1 binding at both Cdkn1a loci, consistent with reduced Cdkn1a levels, but also increases H3K4me2 levels (Fig. 4a, b), consistent with the LSD1 activity as demethylating enzyme for $\mathrm{H} 3 \mathrm{~K} 4$ [30]. Combination of $1,25-\mathrm{D}_{3}$ treatment and LSD1 knockdown significantly increases VDR and reduces DNMT1 binding (Fig. 4a, b) at both Cdkn1a loci, while increasing H3K9Ac at the Cdkn1aVDRE locus, suggesting increased transcription as indicated by Cdkn1a mRNA data. Interestingly, $1,25-\mathrm{D}_{3}$ treatment and LSD1 knockdown reduce H3K4me2 and H3K9Ac levels at the Cdkn1a TSS (Fig. 4a). Since VDR can actively recruit other histone lysine demethylases to modulate transcription [50-53], low levels of LSD1 might facilitate this process. Furthermore, VDR was shown to recruit HDACs to the promoter of target genes [54], which seems to occur in an LSD1-independent manner.

Although E2f1 mRNA levels closely mirror Cdkn1a pattern, E2f1 TSS binding landscape slightly differs from Cdkn1a TSS. Similar to Cdkn1a, 1,25- $\mathrm{D}_{3}$ treatment and LSD1 knockdown increase VDR and reduce DNMT1 binding, consistent with increased gene transcription (Fig. 4c). However, H3K9Ac and H3K4me2 levels are not altered in any condition, suggesting that histone alterations might occur at a different time point or at distal loci surrounding the E2f1 gene.

Overall, these results suggest that in the absence of ligand, LSD1 maintains Cdkn1a expression by preventing
DNMT1 binding and demethylating H3K4 at the Cdkn1a promoter. In the presence of $1,25-\mathrm{D}_{3}$, LSD1 prevents VDR from binding the Cdkn1a and E2f1 TSS and stabilizes DNMT1 favoring its binding at the TSS.

$1,25-\mathrm{D}_{3}$ stimulation does not significantly change VDR levels at the S100g and Cyp24a1 TSS (Fig. 4d, e) suggesting that although short-time treatments show VDR accumulation at the TSS, VDR might shift to multiple distal VDR-responsive elements (VDREs) $[55,56]$ after $24 \mathrm{~h}$ of exposure to $1,25-\mathrm{D}_{3}$. LSD1 knockdown significantly increases DNMT1 binding at the S100g TSS (Fig. 4e) and H3K4me2 levels at the S100g and Cy24a1 TSS (Fig. 4d, e), as expected from the LSD1 demethylase activity. 1,25- $\mathrm{D}_{3}$ treatment increases H3K9Ac levels at the S100g and Cyp24a1 TSS (Fig. 4d, e), consistent with increased transcript levels. Combination of LSD1 knockdown and $1,25-\mathrm{D}_{3}$ treatment reduces H3K9Ac and H3K4me2 levels at the S100g and Cyp24a1 TSS (Fig. 4d, e), supporting qRT-PCR data show reduced S100g and Cyp24a1 transcript levels.

These results suggest that at the S100g TSS, LSD1 limits HDAC activity and leads to increased H3K9Ac, in accordance with the observations made in LSD1 knockout embryos [33]. At the S100 and Cyp24a1 TSS, LSD1 demethylates H3K4 and in cancer cells [30],

These results suggest that LSD1 promotes VDRmediated upregulation of Cyp24a1 and S100 by maintaining H3K9Ac levels.

\section{LSD1 affects DNA methylation of VDR-targeted genes}

Since LSD1 knockdown reduces Cdkn1a transcript levels with a concomitant increase in DNMT1 binding levels, the methylation status of $\mathrm{CpG}$ dinucleotides across the Cdkn1a TSS region was evaluated. BC1A-shCTR and BC1A-shLSD1 cells were treated for $24 \mathrm{~h}$ with $100 \mathrm{nM}$ of $1,25-\mathrm{D}_{3}$ prior DNA extraction and bisulfite sequencing. The number of methylated residues across the TSS did not significantly change (chi-square test, $p=0.3764$ ) (Additional file 1: Table S1, Additional file 1: Figure S7). Therefore, in order to evaluate whether LSD1 and VDR regulate the methylation status of other cancer-related genes, a PCR array containing methylation-specific probes for 94 genes involved with $\mathrm{PCa}$ progression was used. LSD1 knockdown reduces the methylation levels of Fhl1 $(-32.9 \%), N k x 3.1(-17.1 \%)$, Rar-beta $(-17 \%)$, and Tert $(-15.5 \%)$ (Fig. 5c, Additional file 1: Table S2B). These results support LSD1 function in stabilizing DNMT1 by demethylating DNMT1 lysine residue in position 1096 [33]. 1,25- $\mathrm{D}_{3}$ treatment reduced the methylation levels of Cdkn1c and Rprm of 45.2 and 18.3\%, respectively (Fig. 5a, Additional file 1: Table S2A). At the same time, combination of $1,25-\mathrm{D}_{3}$ treatment and LSD1 knockdown reverses the reduction in methylation caused by $1,25-\mathrm{D}_{3}$ treatment in the Cdkn1c and Chd1 genes, increasing the methylation 


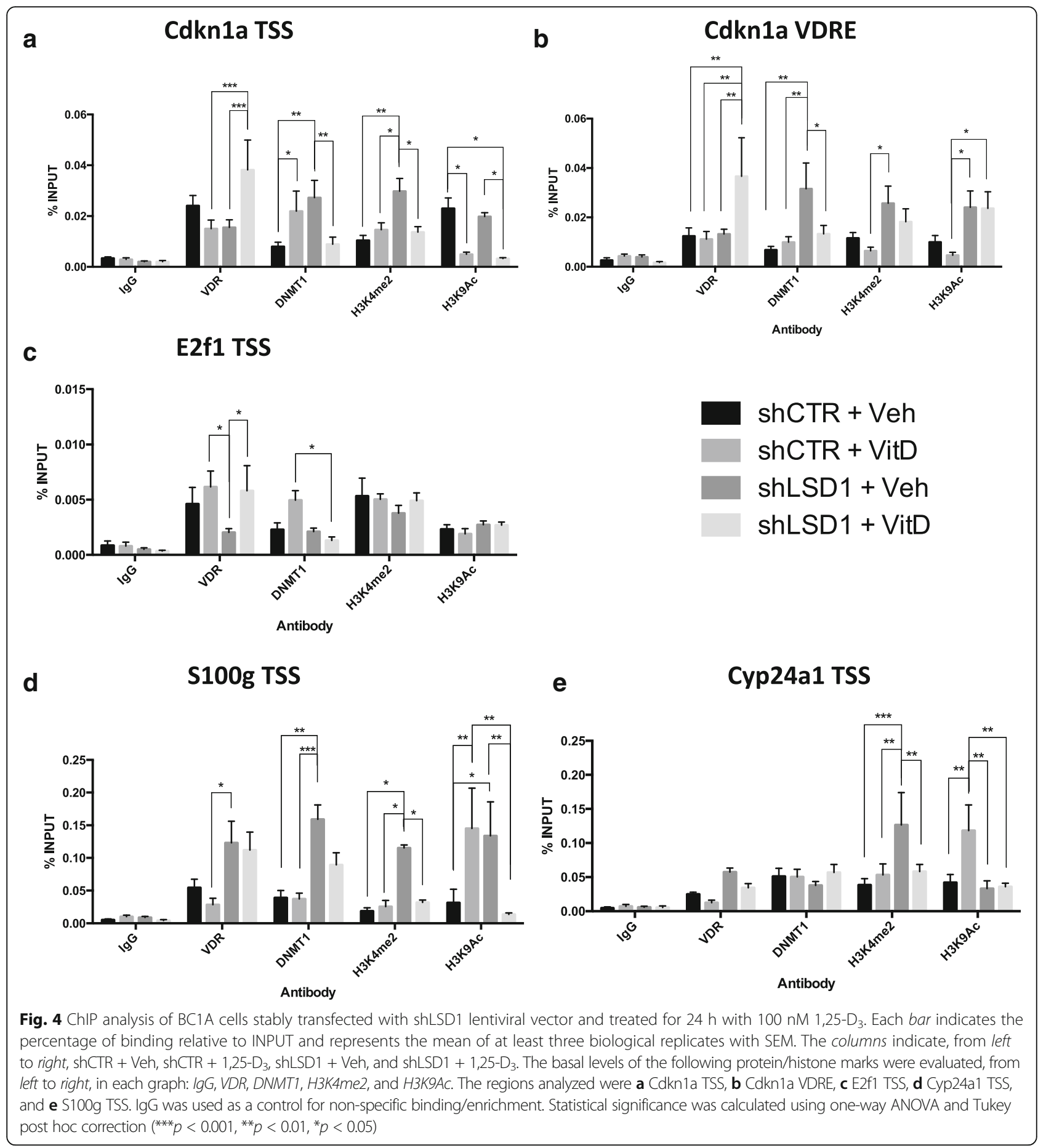

levels of 34.3 and $28 \%$, respectively, while reducing the methylation of Fbln1 of 18\% (Fig. 5d, Additional file 1: Table S2D). Interestingly, $1,25-\mathrm{D}_{3}$ treatment in knockdown cells mostly increased the methylation levels of the genes analyzed (Fig. 5b, Additional file 1: Table S2B), suggesting that VDR might promote secondary posttranslational modification that stabilize DNMT1 [57-61] and promote DNA methylation at specific loci. Overall, these results indicate a relationship between LSD1 and DNMT1 in regulating VDR-dependent DNA methylation in PCa.

\section{LSD1 and DNMT1 status correlate with genome-wide alterations in clinical samples}

Since LSD1, DNMT1, and VDR appear to have interconnected roles in $\mathrm{PCa}$, we sought to identify an 


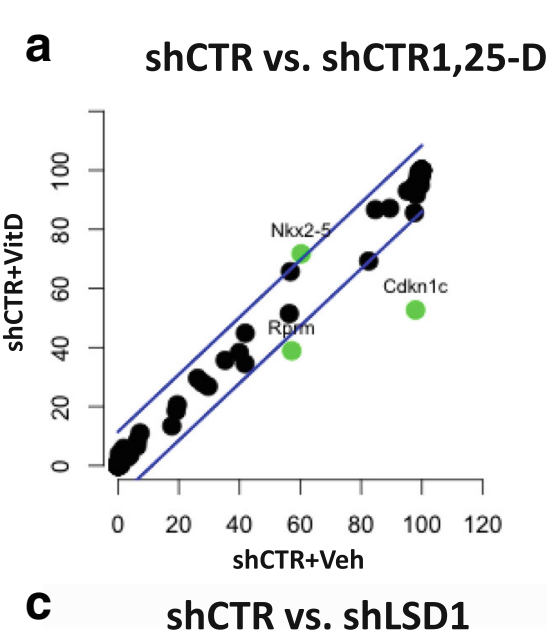

\section{b shLSD1 vs. ShLSD11,25- $\mathrm{D}_{3}$}
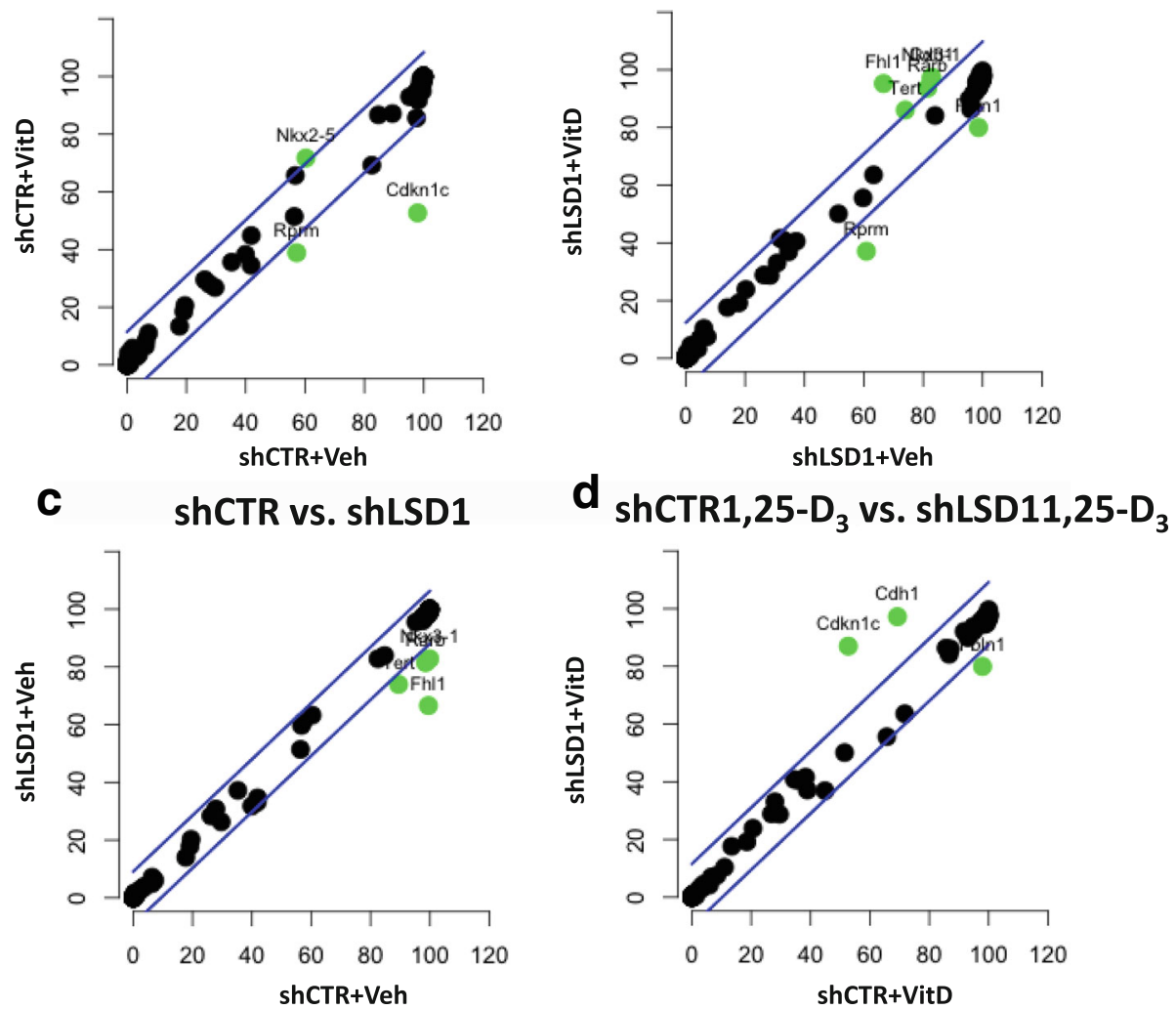

Fig. 5 Visual representation of the methylation changes observed using the Qiagen methylation arrays. A linear model was built to identify differentially methylated regions and the 95\% confidence intervals calculated and plotted (blue lines); green dots show the genes whose methylation significantly differs between the selected conditions. Each quadrant reflects the results listed in Additional file 1: Table S1. a Contribution of vitamin D at basal conditions. b Contribution of LSD1 at basal conditions. c Contribution of vitamin D in knockdown conditions (shLSD1). d Contribution of LSD1 in the presence of vitamin D

LSD1/DNMT1-centered genome-wide signature that has clinical relevance, measured as progression-free survival (PFS) and overall survival (OS). We leveraged data from The Cancer Genome Atlas (TCGA), which include 333 primary PCa samples [62] and 61 metastatic [63]. We first utilized the Regulome Explorer tool to identify genes whose status (expression, methylation, CNV, mutations, protein levels) correlated with LSD1 and DNMT1. Three different statistical approaches were used to evaluate significant correlations based on the data type (details are in the "Methods" section) (Fig. 6a). The top 20 statistically significant genes (Fig. 6b, Additional file 2: File 1), together with VDR, were used to evaluate whether altered expression of this signature correlates with altered patient survival. We queried TCGA survival data for two different patient cohorts, primary and metastatic [63], through the cBioPortal [64]. The results show that patients with altered VDR/LSD1/DNMT1 signature had a shorter PFS in cohort 1 (Fig. 6d) and a shorter OS in cohort 2 (Fig. 6e). To better understand which pathways were affected by our signature, we performed the functional enrichment analysis utilizing Broad's GSEA pathways. The results indicate that the genes in our signature belong to pathways mainly involved in controlling proliferation and cell survival, including DNA replication, M-G1 phase, cell cycle, activation of pre-replicative complex, G2-M checkpoints, and chromatin remodeling (Fig. 6c). Overall, these data suggest that the alterations in the VDR/LSD1/DNMT1 signature lead to alterations in key cellular pathways, whose function directly affects patients' outcome.

\section{Discussion}

LSD1 is a key histone demethylase enzyme whose expression directly reflects disease status in numerous tumor types. In the TRAMP model, the expression of LSD1 and VDR is already elevated at early age where most of the initial tumorigenic transformations occur, leading to hyperplasia of the prostate. Furthermore, high levels of LSD1 and VDR proteins promote tumor growth in the CWR22 xenograft model of $\mathrm{PCa}$, indicating a potential combinatorial role of VDR and LSD1 in promoting tumor establishment and progression. We hypothesized that LSD1 

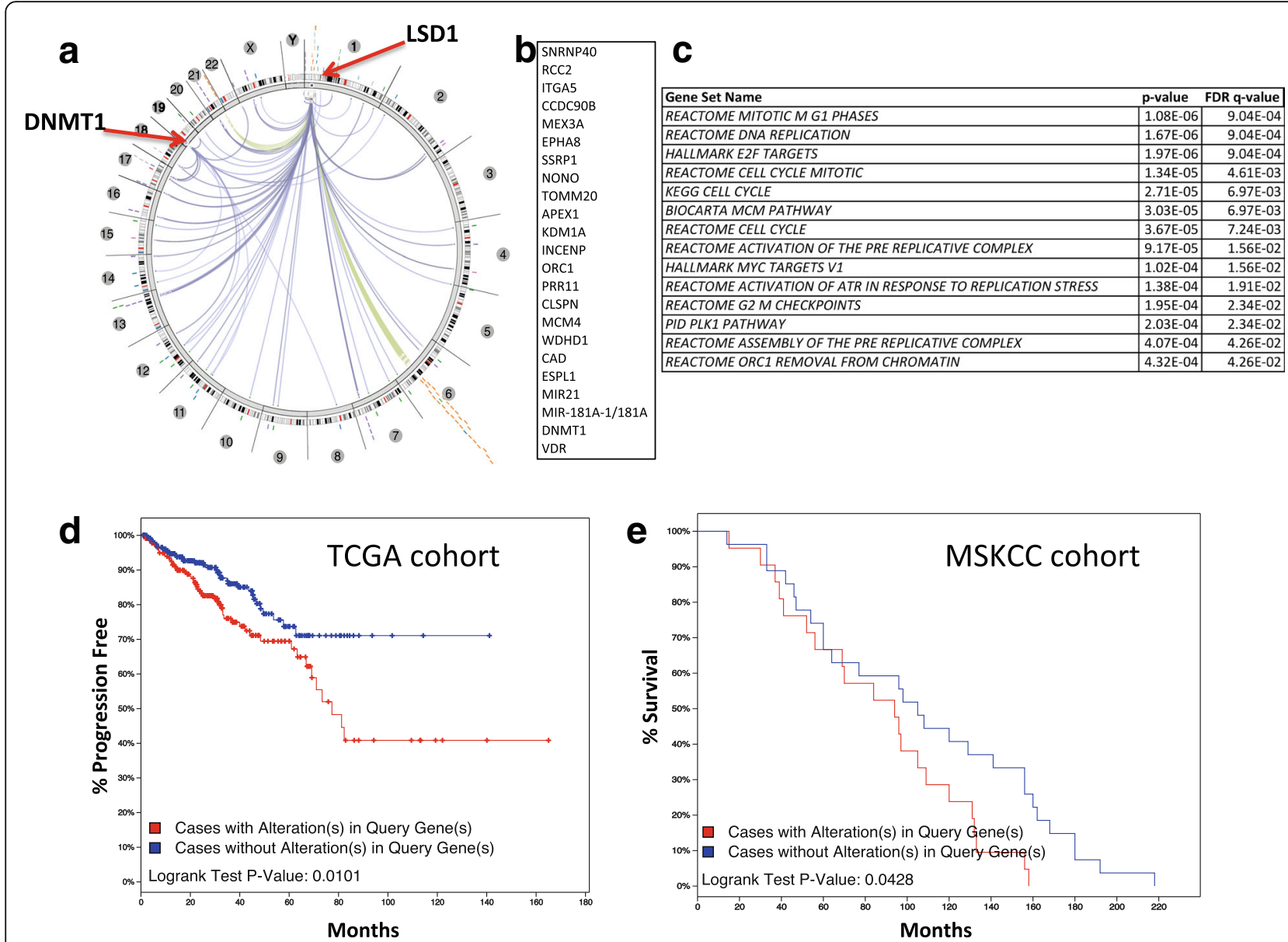

Fig. 6 Graphical overview of the alterations in the LSD1/DNMT1/NDR signature. The Regulome Explorer was used to identify genes correlating with LSD1/DNMT1 status, followed by functional enrichment analysis and survival analysis on two independent TCGA datasets. a Circos plot showing the genes correlating with LSD1 and DNMT1 status. $\mathbf{b}$ List of the genes in the LSD1/DNMT1/NDR signature. $\mathbf{c}$ Functional enrichment analysis of the genes in the LSD1/DNMT1/NDR signature indicating pathway name and origin, $p$ value, and FDR-corrected $q$ value. $\mathbf{d}$, e Kaplan-Meier plot indicating progression-free survival in patients with primary tumor (d) or overall survival in patients with recurrent metastatic tumor (e). The red lines indicate patients with altered LSD1/DNMT1NDR signature ( $z$ score $> \pm 2$ ), and the blue lines indicate patients whose signature is not altered ( $z$ score between -2 and +2 ). Statistical significance was calculated via log-rank test with a threshold of $p<0.05$

plays a key role in the regulation of the VDR-dependent transcription in PCa cells and tested LSD1 as a VDR coregulator. For the first time, LSD1 is identified as dual coregulator, corepressor, and coactivator, for the VDR.

LSD1 is needed for appropriate embryonic development, and LSD1 knockout is embryonically lethal $[33,65]$. LSD1 role in cell growth is also observed in cancer cells, and these data were corroborated by our results, where LSD1 knockdown significantly reduced PCa cell viability. Moreover, genomics analyses of the LSD1-VDR-DNMT1 signature suggest that the mechanism by which LSD1 affects cell growth is through transcriptional control of genes involved with cell cycle and proliferation. Interestingly, the combination of $1,25-\mathrm{D}_{3}$ treatment and LSD1 knockdown further increased $1,25-\mathrm{D}_{3}$ antiproliferative effect in C4-2 cells but not in BC1A cells. These results suggest that in $\mathrm{BC} 1 \mathrm{~A}$ cells, the VDR axis could be inhibited by other coregulatory proteins. Therefore, we sought to investigate the role of LSD1 in regulating the VDR transcriptional complex in BC1A cells. Although we do not show direct physical interaction between LSD1 and VDR, immunoprecipitation experiments show that LSD1 and VDR belong to the same transcriptional complex, suggesting that changes within its components can modulate the direction and magnitude of gene transcription. We utilized the ChIP assay to evaluate the binding of LSD1, VDR, and DNMT1 and the levels of H3K4me2 and H3K9Ac at the TSS of VDR target genes. As LSD1 binds similarly to all loci, increased DNMT1 recruitment is observed in knockdown cells at Cdkn1a and Cyp24a1 TSS. In parallel, LSD1 demethylates lysine 4 on histone H3 [30], supporting the increased H3K4me2 levels observed upon LSD1 knockdown at all but E2f1 promoter. This suggests a locus- and time-specific action of LSD1, which 
was not captured at the E2f1 TSS. Furthermore, it was previously shown that ligand-activated VDR can recruit HDAC1 and HDAC3 to the promoter of target genes [54]. We indeed observed a reduction in H3K9Ac levels after $1,25-\mathrm{D}_{3}$ treatment at the Cdkn1a TSS and at the TSS of Cyp24a1 and S100g upon LSD1 knockdown and 1,25- $\mathrm{D}_{3}$ treatment. These results support lower Cdkn1a mRNA levels observed after 1,25- $\mathrm{D}_{3}$ treatment and in Cyp24a1 and $S 100 g$ mRNA after $1,25-\mathrm{D}_{3}$ treatment in LSD1 knockdown cells. Overall, these results support the hypothesis that in our system, LSD1 modulates gene transcription by altering the recruitment of the transcriptional machinery and the chromatin conformation in the promoter of VDR target genes.

LSD1 was indeed shown to interact with FOXA1 [66] to regulate androgen receptor (AR)-dependent transcription, and it is known to complex with HDACs, RCOR1 [67], GSE1 [67], RBPJ [68], and ZBP1 [69] in a cell-specific manner, supporting the hypothesis that LSD1 might act as a "regulatory anchor" to form and maintain regulatory complexes on the promoter of VDR target genes. Furthermore, as $\mathrm{PCa}$ is hormonally driven, the crosstalk between $A R$ and VDR in prostate cancer was previously investigated, reporting that AR activation inhibits VDR-mediated transcription through the activity of different coregulatory proteins such as prohibitin, ARA70, or ZNF366 [70-72]. As LSD1 has a dual role as corepressor and coactivator for AR and VDR, we believe that the crosstalk between AR/LSD1/VDR is gene- and locus-specific, with potentially different roles in androgen-sensitive vs. castrationrecurrent $\mathrm{PCa}$. In this context, ChIP-Seq analysis of LSD1 binding sites upon AR activation and/or $1,25-\mathrm{D}_{3}$ treatment would be useful to profile the potential LSD1mediated transcriptional feedback between AR and VDR.

A glimpse into the mechanistic function of LSD1 on the chromatin structure comes from studies in breast cancer cells demonstrating that LSD1 is involved in $1,25-\mathrm{D}_{3}$-mediated chromatin looping on the CDKN1A promoter. Knockdown of LSD1 significantly reduced the percentage of looping over untreated cells [73], suggesting that demethylation by LSD1 is essential for correct spatial rearrangement of the transcriptional machinery. Furthermore, LSD1 knockdown in breast cancer cells blocked the estrogen-mediated transcription of TFF1 and GREB1 by inhibiting the interaction between the TFF1 and GREB1 loci and the interchromatin granules containing transcription-related factors [74]. Overall, these data suggest that LSD1 regulatory functions are common to numerous transcription factors and that transcriptional activation or repression is a coordinated event, finely regulated by temporal and spatial factors.

In this study, DNMT1 is identified as an important player in the VDR-LSD1 network. LSD1 knockdown causes a drastic reduction in the methylation levels of
Fhl1, Nkx3.1, Rarb, and Tert, supporting the stabilizing effect of LSD1 on DNMT1. However, it is interesting to note that upon LSD1 knockdown and 1,25- $\mathrm{D}_{3}$ treatment, there is an increase in methylation in Cdh1 and Cdkn1c. This suggests that active VDR might favor secondary post-translational modifications that stabilize DNMT1 $[60,61]$ and consequently promote DNA methylation. In this regard, ChIP sequencing experiments for the DNMT proteins would be useful to profile their dynamic activity across the genome upon LSD1 knockdown.

Complementary correlative computational approaches were used to investigate the role of LSD1, DNMT1, and VDR in a wider, clinical context. Interestingly, genes that belong to the VDR/LSD1/DNMT1 signature enrich pathways that regulate different stages of cell proliferation, including activation of pre-replicative complexes, cell cycle transition, and transcriptional regulation through E2f. Lastly, the translational significance of these results is demonstrated by the fact that alterations in this signature significantly correlate with shorter survival in primary and metastatic prostate cancer.

\section{Conclusions}

In conclusion, we hypothesize a model of VDR/LSD1mediated gene regulation in which LSD1 acts as both

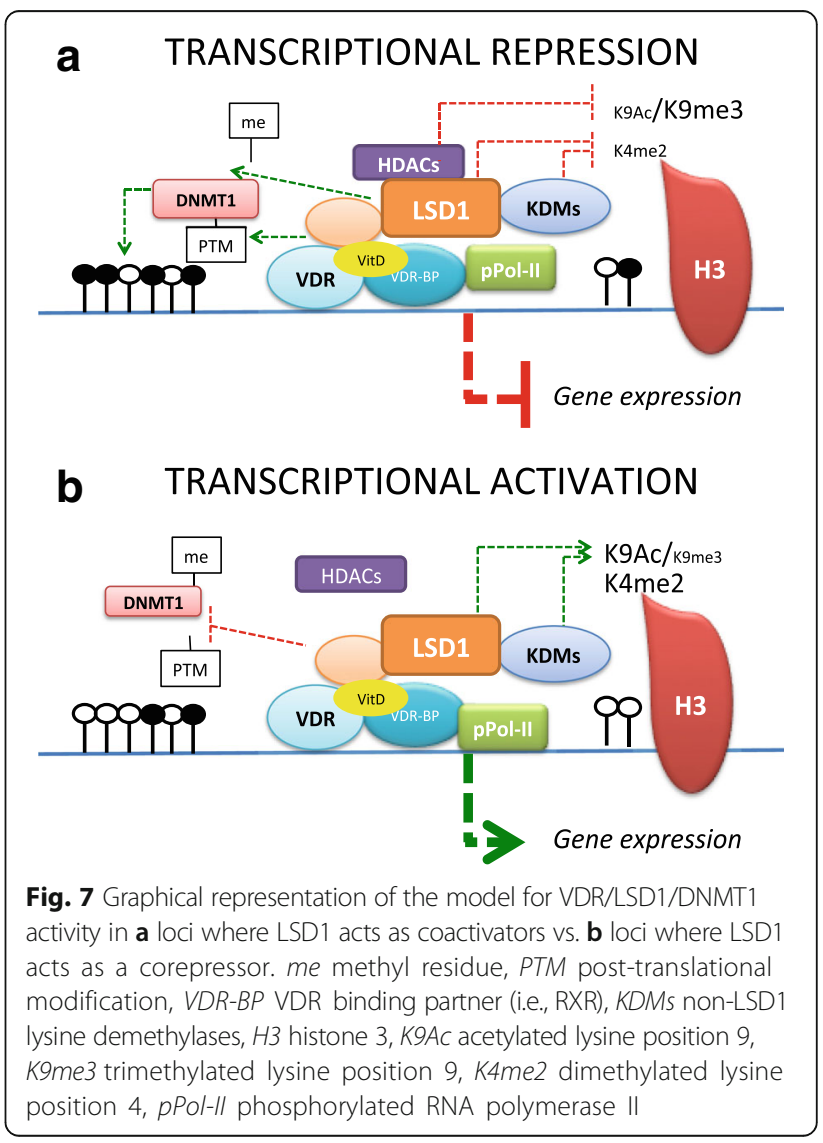


coactivator and corepressor for VDR in the presence of $1,25-\mathrm{D}_{3}$. In the presence of active VDR, the LSD1containing complex represses gene transcription in a locus-specific manner by stabilizing DNMT1, reducing H3K4me2, while HDACs reduce H3K9Ac levels, potentially in favor of the repressive mark H3K9me3. VDR contributes to this mechanism by recruiting secondary epigenetic modifiers to alter the methylomic landscape or histone tail status (Fig. 7a). In loci where LSD1 promotes transcription, target selection changes leading to maintained H3K4me2 levels in the presence of 1,25$\mathrm{D}_{3}$ and LSD1 potentially targeting H3K9me3, favoring H3K9Ac. Furthermore, DNMT1 is demethylated by LSD1, which leads to a less stable protein and consequentially lower methylation of VDR target genes and increased gene transcription (Fig. 7b). Overall, the coordinated action and composition of the regulatory complexes will define the epigenetic status and the transcriptional output, resulting in locus-specific transcriptional activation or repression.

As numerous studies correlate $1,25-\mathrm{D}_{3}$ serum levels with disease status, these results suggest that our LSD1, DNMT1, and VDR signature might mediate an epigenetic lesion that correlates with an altered genomic signature in patient samples. Thus, the contribution of LSD1 in cancer progression could be underestimated and pharmacological inhibition of LSD1 would potentially affect numerous steroid receptor-mediated endocrine pathways; many of which are often altered in cancer.

\section{Additional files}

Additional file 1: Figure S1: $m R N A$ levels of $L s d 1$ in age-matched WT and TRAMP prostates. Each point is the average of five biological replicates with SEM. $\left.{ }^{* *}=p<0.001,{ }^{* * *}=p<0.0001\right)$. Figure $\mathbf{S 2}$. Representative IHC images of CWR22 tumors stained for LSD1 (left) or VDR (right). Mice are divided into HIGH (top) or LOW (bottom) depending upon protein abundance. Figure S3. Knockdown efficiency. A) siRNA and $B, C)$ shRNA against $L s d 1$ in $B C 1 A(A, B)$ and $C 4-2$ cells (C) measured by qRT-PCR-TaqMan and D, F) cropped WB. $\left({ }^{* * *} p<0.001,{ }^{* *} p<0.01\right.$, ${ }^{*} p<0.05$, Student's $t$ test). Figure S4. qRT-PCR for A) E2f1 and (dkn1a at $24 \mathrm{~h}$ and B) Cyp24a1 and S100g at $4 \mathrm{~h}$. Each bar is the mean of at least three biological replicates with SEM, as fold changes of 1,25-D3 vs. Veh treated samples $\left({ }^{* * *} p<0.001,{ }^{* *} p<0.01,{ }^{*} p<0.05\right)$. Figure S5. Map of the regions analyzed via ChIP (in red) for Cdkn1a, E2f1, S100g, and Cyp24a1. Figure S6. ChIP analysis for LSD1 in BC1A cells. Each bar is the mean of at least three biological replicates with SEM. X-axis indicates the locus, Y-axis indicates the fold enrichment over INPUT, lgG was used as control for aspecific binding. Statistical significance was calculated comparing LSD1 with IgG within each condition using Student's t test. $\left({ }^{* *} p<0.01,{ }^{*} p<0.05\right)$. Figure S7. Map of the CpG sites analyzed via bisulfite sequencing at the Cdkn1a TSS. Each shade of gray represents the average methylation level across four biological replicates. The position of each site is indicated at the bottom. Table S1. Results from bisulfite sequencing. Table S2. LSD1- and vitamin D-driven changes in DNA methylation in PCa-related genes. Table S3. Primer sequences used for ChIP analysis. (DOCX $20587 \mathrm{~kb}$ )

Additional file 2: Raw results from the regulome explorer analysis for LSD1 and DNMT1. (CSV $36 \mathrm{~kb}$ )

\section{Abbreviations}

1,25(OH) 2 - $\mathrm{D}_{3}$ : Vitamin D; ChIP: Chromatin immunoprecipitation; DNMT1: DNA methyltransferase 1; LSD1/KDM1A: Lysine-specific demethylase 1A;

OS: Overall survival; PCa: Prostate cancer; PFS: Progression-free survival;

TCGA: The Cancer Genome Atlas; VDR: Vitamin D receptor

\section{Acknowledgements}

Not applicable

\section{Funding}

This study is funded by the SB American Italian Cancer Foundation 57-1234-01 \& 57-1234-02, Department of Defense W81XWH-13-1-0276; PC121785, BAF National Institute of Health 5R01CA095367-08, and Cancer Center Support Grant 2P30CA016056-37.

\section{Availability of data and materials}

Not applicable.

\section{Authors' contributions}

$\mathrm{SB}$ and BAF designed the experiments and wrote the manuscript with $\mathrm{MM}$ and DJS. SB performed the gene expression analyses, ChIP experiments, methyl array experiments, and computational analyses. EK performed the $\mathrm{IHC}$ and IP experiments and the methylation experiments with SB. BG and SB performed the in vivo experiments. JW performed the proliferation assay experiments with and knockdown in C4-2 cells with SB. TW performed the knockdown experiments in BC1A cells and proliferation assays with SB. MM contributed in the designing of the experimental protocol for the in vivo experiments and established the BC1A cell line with BAF. DJS designed the methylation experiments that were performed by EK and SB. All authors read and approved the final manuscript.

Ethics approval and consent to participate

Not applicable.

\section{Consent for publication}

Not applicable.

\section{Competing interests}

The authors declare that they have no competing interests.

\section{Publisher's Note}

Springer Nature remains neutral with regard to jurisdictional claims in published maps and institutional affiliations.

\section{Author details}

${ }^{1}$ Center for Immunotherapy, Roswell Park Cancer Institute, Elm and Carlton St, Buffalo, NY 14263, USA. ${ }^{2}$ Department of Pharmacology and Therapeutics, Roswell Park Cancer Institute, Elm and Carlton St, Buffalo, NY 14263, USA. ${ }^{3}$ Department of Cancer Genetics, Roswell Park Cancer Institute, Elm and Carlton St, Buffalo, NY 14263, USA.

Received: 19 June 2017 Accepted: 3 August 2017

Published online: 11 August 2017

\section{References}

1. Siegel R, Ma J, Zou Z, Jemal A. Cancer statistics, 2014. CA Cancer J Clin. 2014;64(1):9-29.

2. Jones $G$, Strugnell SA, DeLuca HF. Current understanding of the molecular actions of vitamin D. Physiol Rev. 1998:78(4):1193-231.

3. Darwish HM, DeLuca HF. Identification of a 1,25-dihydroxyvitamin D3-response element in the $5^{\prime}$-flanking region of the rat calbindin D-9k gene. Proc Natl Acad Sci U S A. 1992;89(2):603-7.

4. Lam NN, Triliana R, Sawyer RK, Atkins GJ, Morris HA, O'Loughlin PD, et al. Vitamin $\mathrm{D}$ receptor overexpression in osteoblasts and osteocytes prevents bone loss during vitamin D-deficiency. J Steroid Biochem Mol Biol. 2014; 144(Part A):128-31.

5. van de Peppel J, van Leeuwen JP. Vitamin D and gene networks in human osteoblasts. Front Physiol. 2014:5:137.

6. Zhou TB, Jiang ZP, Huang MF, Zhang R. Association of vitamin D receptor gene polymorphism with the urine calcium level in nephrolithiasis patients. J Recept Signal Transduct Res. 2014:1-5. 
7. Kuhne H, Schutkowski A, Weinholz S, Cordes C, Schierhorn A, Schulz K, et al Vitamin $D$ receptor regulates intestinal proteins involved in cell proliferation, migration and stress response. Lipids Health Dis. 2014;13:51.

8. Yuan FN, Valiyaparambil J, Woods MC, Tran H, Pant R, Adams JS, et al. Vitamin $\mathrm{D}$ signaling regulates oral keratinocyte proliferation in vitro and in vivo. Int J Oncol. 2014:44(5):1625-33.

9. Girgis CM, Clifton-Bligh RJ, Mokbel N, Cheng K, Gunton JE. Vitamin D signaling regulates proliferation, differentiation, and myotube size in C2C12 skeletal muscle cells. Endocrinology. 2014;155(2):347-57.

10. Bikle DD, Jiang Y. The protective role of vitamin D signaling in non-melanoma skin cancer. Cancers. 2013;5(4):1426-38.

11. Ryynanen J, Seuter S, Campbell MJ, Carlberg C. Gene regulatory scenarios of primary 1,25-dihydroxyvitamin D3 target genes in a human myeloid leukemia cell line. Cancers (Basel). 2013;5(4):1221-41.

12. Saramaki A, Banwell CM, Campbell MJ, Carlberg C. Regulation of the human p21(waf1/cip1) gene promoter via multiple binding sites for p53 and the vitamin D3 receptor. Nucleic Acids Res. 2006;34(2):543-54.

13. Boyle BJ, Zhao XY, Cohen P, Feldman D. Insulin-like growth factor binding protein-3 mediates 1a,25-dihydroxyvitamin $D(3)$ growth inhibition in the LNCaP prostate cancer cell line through p21/WAF1. J Urol. 2001;165(4): 1319-24.

14. Eelen $G$, Verlinden $L$, van Camp $M$, van Hummelen $P$, Marchal $K$, de Moor B, et al. The effects of 1a,25-dihydroxyvitamin D3 on the expression of DNA replication genes. J Bone Miner Res. 2004;19(1):133-46.

15. Larriba MJ, Ordonez-Moran P, Chicote I, Martin-Fernandez G, Puig I, Munoz A, et al. Vitamin D receptor deficiency enhances Wnt/beta-catenin signaling and tumor burden in colon cancer. PLoS One. 2011;6(8):e23524.

16. Pan $\mathrm{Q}$, Simpson RU. c-myc intron element-binding proteins are required for 1, 25-dihydroxyvitamin D3 regulation of c-myc during $\mathrm{HL}-60$ cell differentiation and the involvement of HOXB4. J Biol Chem. 1999;274(13): 8437-44.

17. Kizildag S, Ates H, Kizildag S. Treatment of K562 cells with 1,25-dihydroxyvitamin D3 induces distinct alterations in the expression of apoptosis-related genes BCL2, BAX, BCLXL, and p21. Ann Hematol. 2010;89(1):1-7.

18. Alagbala AA, Moser MT, Johnson CS, Trump DL, Foster BA. Characterization of vitamin $D$ insensitive prostate cancer cells. JSteroid BiochemMolBiol. 2007;103(3-5):712-6.

19. Battaglia S, Maguire O, Thorne $J$, Hornung LB, Doig CL, Liu S, et al. Elevated NCOR1 disrupts PPARalpha/gamma signaling in prostate cancer and forms a targetable epigenetic lesion. Carcinogenesis. 2010;31(9):1650-60.

20. Toptas B, Kafadar AM, Cacina C, Turan S, Yurdum LM, Yigitbasi N, et al. The vitamin D receptor (VDR) gene polymorphisms in Turkish brain cancer patients. Biomed Res Int. 2013;2013:295791.

21. Guy M, Lowe LC, Bretherton-Watt D, Mansi JL, Peckitt C, Bliss J, et al. Vitamin $D$ receptor gene polymorphisms and breast cancer risk. Clin Cancer Res. 2004;10(16):5472-81.

22. Haussler MR, Haussler CA, Jurutka PW, Thompson PD, Hsieh JC, Remus LS, et al. The vitamin $\mathrm{D}$ hormone and its nuclear receptor: molecular actions and disease states. J Endocrinol. 1997:154(Suppl):S57-73.

23. Khanim FL, Gommersall LM, Wood VH, Smith KL, Montalvo L, O'Neill LP, et al. Altered SMRT levels disrupt vitamin D3 receptor signalling in prostate cancer cells. Oncogene. 2004;23(40):6712-25.

24. Banwell CM, O'Neill LP, Uskokovic MR, Campbell MJ. Targeting 1alpha,25-dihydroxyvitamin D3 antiproliferative insensitivity in breast cancer cells by co-treatment with histone deacetylation inhibitors. JSteroid Biochem Mol Biol. 2004;89-90(1-5):245-9.

25. Abedin SA, Banwell CM, Colston KW, Carlberg C, Campbell MJ. Epigenetic corruption of VDR signalling in malignancy. Anticancer Res. 2006;26(4A):2557-66.

26. Malinen M, Saramaki A, Ropponen A, Degenhardt T, Vaisanen S, Carlberg C. Distinct HDACs regulate the transcriptional response of human cyclin-dependent kinase inhibitor genes to Trichostatin A and 1alpha,25-dihydroxyvitamin D3. Nucleic Acids Res. 2008;36(1):121-32.

27. Doig CL, Singh PK, Dhiman VK, Thorne JL, Battaglia S, Sobolewski M, et al. Recruitment of NCOR1 to VDR target genes is enhanced in prostate cancer cells and associates with altered DNA methylation patterns. Carcinogenesis. 2013;34(2):248-56

28. Carlberg C, Dunlop TW. The impact of chromatin organization of vitamin D target genes. Anticancer Res. 2006;26(4A):2637-45.

29. Essa S, Reichrath S, Mahlknecht U, Montenarh M, Vogt T, Reichrath J. Signature of VDR miRNAs and epigenetic modulation of vitamin D signaling in melanoma cell lines. Anticancer Res. 2012;32(1):383-9.
30. Shi Y, Lan F, Matson C, Mulligan P, Whetstine JR, Cole PA, et al. Histone demethylation mediated by the nuclear amine oxidase homolog LSD1. Cell. 2004;119(7):941-53

31. Metzger E, Wissmann M, Yin N, Muller JM, Schneider R, Peters AH, et al. LSD1 demethylates repressive histone marks to promote androgenreceptor-dependent transcription. Nature. 2005;437(7057):436-9.

32. Huang J, Sengupta R, Espejo AB, Lee MG, Dorsey JA, Richter M, et al. p53 is regulated by the lysine demethylase LSD1. Nature. 2007;449(7158):105-8.

33. Wang J, Hevi S, Kurash JK, Lei H, Gay F, Bajko J, et al. The lysine demethylase LSD1 (KDM1) is required for maintenance of global DNA methylation. Nat Genet. 2009;41(1):125-9.

34. Hayami S, Kelly JD, Cho HS, Yoshimatsu M, Unoki M, Tsunoda T, et al. Overexpression of LSD1 contributes to human carcinogenesis through chromatin regulation in various cancers. Int J Cancer. 2011;128(3):574-86.

35. Wang $Y$, Zhang $H$, Chen $Y$, Sun $Y$, Yang F, Yu W, et al. LSD1 is a subunit of the NuRD complex and targets the metastasis programs in breast cancer. Cell. 2009:138(4):660-72.

36. Singh MM, Manton CA, Bhat KP, Tsai WW, Aldape K, Barton MC, et al. Inhibition of LSD1 sensitizes glioblastoma cells to histone deacetylase inhibitors. Neuro-Oncology. 2011;13(8):894-903.

37. Willmann D, Lim S, Wetzel S, Metzger E, Jandausch A, Wilk W, et al. Impairment of prostate cancer cell growth by a selective and reversible LSD1 inhibitor. Int J Cancer. 2012;

38. Greenberg NM, DeMayo F, Finegold MJ, Medina D, Tilley WD, Aspinall JO, et al. Prostate cancer in a transgenic mouse. Proc Natl Acad Sci U S A. 1995; 92(8):3439-43.

39. Gingrich JR, Barrios RJ, Morton RA, Boyce BF, DeMayo FJ, Finegold MJ, et al. Metastatic prostate cancer in a transgenic mouse. Cancer Res. 1996;56(18): 4096-102.

40. R Core Team. R: A Language and Environment for Statistical Computing. Vienna: R Foundation for Statistical Computing; 2016. https://www.R-project.org.

41. Terry M Therneau. A Package for Survival Analysis in S. version 2.38. 2015. https://CRAN.R-project.org/package=survival.

42. Zibetti C, Adamo A, Binda C, Forneris F, Toffolo E, Verpelli C, et al. Alternative splicing of the histone demethylase LSD1/KDM1 contributes to the modulation of neurite morphogenesis in the mammalian nervous system. J Neurosci. 2010;30(7):2521-32.

43. Lim S, Janzer A, Becker A, Zimmer A, Schule R, Buettner R, et al. Lysine-specific demethylase 1 (LSD1) is highly expressed in ER-negative breast cancers and a biomarker predicting aggressive biology. Carcinogenesis. 2010;31(3):512-20.

44. Schulte JH, Lim S, Schramm A, Friedrichs N, Koster J, Versteeg R, et al. Lysine-specific demethylase 1 is strongly expressed in poorly differentiated neuroblastoma: implications for therapy. Cancer Res. 2009. 69(5):2065-71.

45. Kahl P, Gullotti L, Heukamp LC, Wolf S, Friedrichs N, Vorreuther R, et al. Androgen receptor coactivators lysine-specific histone demethylase 1 and four and a half LIM domain protein 2 predict risk of prostate cancer recurrence. Cancer Res. 2006;66(23):11341-7.

46. Perissi V, Rosenfeld MG. Controlling nuclear receptors: the circular logic of cofactor cycles. Nat Rev Mol Cell Biol. 2005;6(7):542-54

47. Weston AD, Blumberg B, Underhill TM. Active repression by unliganded retinoid receptors in development: less is sometimes more. JCell Biol. 2003; 161(2):223-8.

48. Jones G, Prosser DE, Kaufmann M. 25-hydroxyvitamin D-24-hydroxylase (CYP24A1): its important role in the degradation of vitamin D. Arch Biochem Biophys. 2012;523(1):9-18.

49. Nicholson TB, Chen T. LSD1 demethylates histone and non-histone proteins. Epigenetics. 2009;4(3):129-32

50. Hoffmann I, Roatsch M, Schmitt ML, Carlino L, Pippel M, Sippl W, et al. The role of histone demethylases in cancer therapy. Mol Oncol. 2012;6(6):683-703.

51. Rotili D, Mai A. Targeting histone demethylases: a new avenue for the fight against cancer. Genes \& cancer. 2011;2(6):663-79.

52. Hojfeldt JW, Agger K, Helin K. Histone lysine demethylases as targets for anticancer therapy. Nat Rev Drug Discov. 2013:12(12):917-30.

53. Cloos PA, Christensen J, Agger K, Helin K. Erasing the methyl mark: histone demethylases at the center of cellular differentiation and disease. Genes Dev. 2008;22(9):1115-40

54. Milovanovic M, Heine G, Hallatschek W, Opitz B, Radbruch A, Worm M. Vitamin $D$ receptor binds to the epsilon germline gene promoter and exhibits transrepressive activity. J Allergy Clin Immunol. 2010;126(5): 1016-23. 23 e1-4 
55. Meyer MB, Goetsch PD, Pike JW. A downstream intergenic cluster of regulatory enhancers contributes to the induction of CYP24A1 expression by 1alpha,25-dihydroxyvitamin D3. J Biol Chem. 2010;285(20): 15599-610.

56. Pike JW, Meyer MB. Regulation of mouse Cyp24a1 expression via promoter-proximal and downstream-distal enhancers highlights new concepts of 1,25-dihydroxyvitamin D(3) action. Arch Biochem Biophys. 2012;523(1):2-8.

57. Lee B, Muller MT. SUMOylation enhances DNA methyltransferase 1 activity. The Biochemical journal. 2009;421(3):449-61.

58. Lavoie G, St-Pierre Y. Phosphorylation of human DNMT1: implication of cyclin-dependent kinases. Biochem Biophys Res Commun. 2011;409(2):187-92.

59. Esteve PO, Chang Y, Samaranayake M, Upadhyay AK, Horton JR, Feehery GR, et al. A methylation and phosphorylation switch between an adjacent lysine and serine determines human DNMT1 stability. Nat Struct Mol Biol. 2011;18(1):42-8.

60. Lin RK, Wang YC. Dysregulated transcriptional and post-translational control of DNA methyltransferases in cancer. Cell Biosci. 2014;4:46.

61. Scott A, Song J, Ewing R, Wang Z. Regulation of protein stability of DNA methyltransferase 1 by post-translational modifications. Acta Biochim Biophys Sin Shanghai. 2014;46(3):199-203.

62. Cancer Genome Atlas Research N. The molecular taxonomy of primary prostate cancer. Cell. 2015;163(4):1011-25.

63. Grasso CS, Wu YM, Robinson DR, Cao X, Dhanasekaran SM, Khan AP, et al. The mutational landscape of lethal castration-resistant prostate cancer. Nature. 2012:487(7406):239-43.

64. Gao J, Aksoy BA, Dogrusoz U, Dresdner G, Gross B, Sumer SO, et al. Integrative analysis of complex cancer genomics and clinical profiles using the cBioPortal. Sci Signal. 2013;6(269):pl1.

65. Foster CT, Dovey OM, Lezina L, Luo JL, Gant TW, Barlev N, et al. Lysine-specific demethylase 1 regulates the embryonic transcriptome and COREST stability. Mol Cell Biol. 2010;30(20):4851-63.

66. Cai C, He HH, Gao S, Chen S, Yu Z, Gao Y, et al. Lysine-specific demethylase 1 has dual functions as a major regulator of androgen receptor transcriptional activity. Cell Rep. 2014;9(5):1618-27.

67. Joshi P, Greco TM, Guise AJ, Luo Y, Yu F, Nesvizhskii Al, et al. The functional interactome landscape of the human histone deacetylase family. Mol Syst Biol. 2013;9:672

68. Yatim A, Benne C, Sobhian B, Laurent-Chabalier S, Deas O, Judde JG, et al. NOTCH1 nuclear interactome reveals key regulators of its transcriptional activity and oncogenic function. Mol Cell. 2012;48(3):445-58.

69. Li S, Wang L, Berman M, Kong YY, Dorf ME. Mapping a dynamic innate immunity protein interaction network regulating type I interferon production. Immunity. 2011;35(3):426-40.

70. Mooso B, Madhav A, Johnson S, Roy M, Moore ME, Moy C, et al. Androgen receptor regulation of vitamin $\mathrm{D}$ receptor in response of castration-resistant prostate cancer cells to 1alpha-hydroxyvitamin D5-a calcitriol analog. Genes Cancer. 2010;1(9):927-40.

71. Ting HJ, Bao BY, Hsu CL, Lee YF. Androgen-receptor coregulators mediate the suppressive effect of androgen signals on vitamin $D$ receptor activity. Endocrine. 2005;26(1):1-9.

72. Ansems M, Karthaus N, Hontelez S, Aalders T, Looman MW, Verhaegh GW, et al. DC-SCRIPT: AR and VDR regulator lost upon transformation of prostate epithelial cells. Prostate. 2012;72(16):1708-17.

73. Saramaki A, Diermeier S, Kellner R, Laitinen H, Vaisanen S, Carlberg C. Cyclical chromatin looping and transcription factor association on the regulatory regions of the p21 (CDKN1A) gene in response to 1alpha,25dihydroxyvitamin D3. J Biol Chem. 2009;284(12):8073-82.

74. Hu Q, Kwon YS, Nunez E, Cardamone MD, Hutt KR, Ohgi KA, et al. Enhancing nuclear receptor-induced transcription requires nuclear motor and LSD1-dependent gene networking in interchromatin granules. Proc Natl Acad Sci U S A. 2008;105(49):19199-204.

\section{Submit your next manuscript to BioMed Central and we will help you at every step:}

- We accept pre-submission inquiries

- Our selector tool helps you to find the most relevant journal

- We provide round the clock customer support

- Convenient online submission

- Thorough peer review

- Inclusion in PubMed and all major indexing services

- Maximum visibility for your research

Submit your manuscript at www.biomedcentral.com/submit
Biomed Central 